\title{
Cuidados em pacientes com doença de Alzheimer na odontologia
}

\author{
Care in patients with Alzheimer's disease in dentistry \\ Cuidado en pacientes con enfermedad de Alzheimer en odontología
}

José Milton de Aquino e Silva Neto ${ }^{1 *}$, Suelly Maria Silva dos Praseres ${ }^{1}$, Victor Raphael Santos ${ }^{1}$, Weizia Gomes da Rocha ${ }^{1}$, Gerson Souza Cavalcante Guimarães Neto ${ }^{1}$, Marília Oliveira Costa ${ }^{1}$, Michelle Leão Bittencourt Brandão Medeiros ${ }^{1}$, Tayguara Cerqueira Cavalcanti'.

\section{RESUMO}

Objetivo: Demonstrar as estratégias de atenção e técnicas que são utilizadas no acompanhamento odontológico de pacientes com doença de Alzheimer (DA). Revisão bibliográfica: Os pacientes que sofrem com a DA demonstram possuir uma patologia dos quais promovem a ausência gradativa das funcionalidades que atingem a parte neurológica. Até os dias de hoje sua causa não é conhecida e os recursos terapêuticos são direcionados a melhora de sua sintomatologia, nos quais os cuidados devem serem feitos por uma equipe multiprofissional que envolvem desde neurologistas até cirurgiões dentistas. Os cuidados na cavidade oral são de suma importância para esses pacientes, tendo que os cuidadores ou familiares devem ficar atentos a cada detalhe, a elaboração de um plano odontológico deve ser pertinente com perspectiva preventiva, buscando conduzir-se a partir do diagnóstico da respectiva patologia, visando desta maneira tornar a vida do paciente mais agradável. Considerações finais: No sentindo de se estabelecer um seguimento favorável para a saúde desses indivíduos, os CD precisa entender o dinamismo da, sendo levado em consideração a forma particularizada que ocorre de um paciente para outro, esses profissionais precisam estar devidamente capacitados, buscando atender de forma mais humanizada possível.

Palavras-chave: Assistência ambulatorial, Doença de alzheimer, Saúde bucal, Assistência odontológica.

\section{ABSTRACT}

Objective: Demonstrate the care strategies and techniques that are used in the dental care of patients with Alzheimer's disease (DA). Literature review: Patients suffering from DA demonstrate a pathology, which promotes the gradual absence of functionalities that affect the neurological part. Until today, its cause is not known and the therapeutic resources are aimed at improving its symptoms, in which a multidisciplinary team involving neurologists to dentists must carry out care. Care in the oral cavity is of paramount importance for these patients, as caregivers or family members must be attentive to every detail, the preparation of a dental plan must be relevant with a preventive perspective, seeking to conduct themselves from the diagnosis of the respective pathology , aiming in this way to make the patient's life more pleasant. Final considerations: In the sense of establishing a favorable follow-up for the health of these individuals, the DCs need to understand the dynamism of AD, taking into account the particular form that occurs from one patient to another, these professionals need to be properly trained, seeking to attend more humanized as possible.

Keywords: Ambulatory care, Alzheimer disease, Oral health, Dental care.

\section{RESUMEN}

Objetivo: Demostrar las estrategias y técnicas de atención que se utilizan en el cuidado dental de pacientes con enfermedad de Alzheimer (DA). Revisión bibliográfica: Los pacientes que padecen EA presentan una patología, que favorece la paulatina ausencia de funcionalidades que afecten a la parte neurológica. Hasta el día de hoy, se desconoce su causa y los recursos terapéuticos están dirigidos a mejorar sus síntomas, en los que la atención debe ser realizada por un equipo multidisciplinar que involucra desde neurólogos hasta odontólogos. El cuidado en la cavidad bucal es de suma importancia para estos pacientes, ya que los cuidadores o familiares deben estar atentos a cada detalle, la elaboración de un plan dental debe ser relevante con una perspectiva preventiva, buscando conducirse desde el diagnóstico de la patología respectiva, con el objetivo de hacer más agradable la vida del paciente. Consideraciones finales: En el sentido de establecer un seguimiento favorable para la salud de estos individuos, las CD necesitan comprender el dinamismo de la EA, teniendo en cuenta la forma particular que se da de un paciente a otro, estos profesionales necesitan estar debidamente capacitados, buscando atender más humanizado como sea posible.

Palabras clave: Atención ambulatoria, Enfermedad de alzheimer, Salud bucal, Atención odontológica.

${ }^{1}$ Centro Universitário CESMAC (CESMAC), Maceió - AL. `E-mail: milton_neto_166@hotmail.com

SUBMETIDO EM: 8/2020

ACEITO EM: 9/2020

PUBLICADO EM: 12/2020 


\section{INTRODUÇÃO}

Um dos aspectos da doença de Alzheimer (DA) é a forma em que ocasiona o transtorno neurodegenerativo dos quais provoca a demência do paciente portador, sendo encarada como uma patologia continua do encéfalo, dos quais leva à perda de memória e do discernimento em que provoca efeitos avassaladores (SILVA RAC, et al., 2015). Portadores de DA habitualmente são caracterizados por demostrarem ausência gradativa e evolutiva da memória e de competências em que provoca prejuízo no desempenho cognitivo, intelectual, funcional e social (ILHA S, et al., 2010).

Com o avanço gradativo dessa enfermidade, os pacientes demostram alterações nas características psicológicas demonstrando-se assim formas e padrões diferentes de pensar, sentir e agir, por exemplo: mau controle da autonomia, opinar em determinados assuntos por impulsos, intranquilidade sem motivos aparentes, tornam-se mais agressivos, perda de confiança, elevado grau da insistência e persistência, distúrbios mentais, impaciência, alteração repentina de humor, fobia, aversão, enraivecimento e cuidados ininterruptos de acompanhantes ou familiares (MONTANDON AFB, et al., 2017).

A análise clínica e laboratorial para o diagnóstico dessa enfermidade é estabelecida através da observação clínica, em que é demonstrado e ressaltado através do avanço do acrescentamento das diminuições nos afazeres do dia a dia (ILHA S, et al., 2010). Até os dias atuais não se possui a cura do paciente portado da doença de Alzheimer e os recursos terapêuticos se baseiam em uma metodologia de tratamento que visa a melhoria da cognição nos quais dá ênfase a percepção, a atenção, associação dos pacientes, buscando assim prolongar o seu avanço. Ficando atento as sintomatologias e as alterações comportamentais a contar do uso de fármacos que influenciam de forma direta na saúde bucal por propiciar à diminuição do fluxo salivar (FEART C, et al., 2017).

Assim sendo, o desprovimento da saúde na cavidade bucal desses indivíduos portadores, frequentemente, estão diretamente relativos a problemas com cárie e doenças periodontais, por causa da carência do controle do acúmulo de biofilmes e presença grande de placas bacterianas e a respectiva presença de xerostomia ocasionadas por medicamentos. Não bastante, ainda é encontrado presença de traumatismo na mucosa dos quais são corriqueiros em razão do uso de próteses dentárias mal adaptadas e desgastadas (TURNER LN, et al., 2008). É bastante importante que o paciente portador da DA esteja sendo acompanhado e examinados por um grupo multiprofissional em que estejam presentes os médicos especializados nessa área, enfermeiros e cirurgiões dentistas qualificados (DIAS MHMS e FONSECA SC, 2011).

Deste modo, o presente estudo possui como indispensável parâmetro, através de uma revisão de literatura, demonstrar as estratégias de atenção e as técnicas que são utilizadas que ocorrem em pacientes com Doença de Alzheimer não só no contexto geral, mas sim observar também os aspectos bucais no sentindo de se estabelecer um seguimento favorável para a saúde desses indivíduos, demonstrando que o CD precisa entender o dinamismo da DA, sendo levado em consideração a forma particularizada que ocorre de um paciente para outro, estando eles devidamente capacitados, buscando atender de forma mais humanizada possível.

\section{REVISÃO BIBLIOGRÁFICA}

\section{Manifestações clínicas da Doença de Alzheimer}

Um dos fatores que ocasionam a demência é ocasionada devido uma desregularização neurodegenerativa dos quais prejudica de forma direta o Sistema Nervoso Central, de modo gradual e quadro inconvertível, a DA é a patologia que ocorre com mais frequência em pessoas idosas. Os sinais que são mais representativos dessa doença acontece a cerca de $40 \%$ nos achados, dos quais possuem uma faixa etária igual ou superior a 85 anos de idade, dos quais são mais corriqueiros em pacientes hispânicos, indivíduos melanoderma, e pessoas do sexo feminino (MIRANDA AF e MONTENEGRO FLB, 2009).

Esse desvio de funcionalidade dos quais são acarretados nos pacientes com DA sensibiliza principalmente os mecanismos das funções intelectuais, ocasionando gradativamente a deterioração em que prejudica a memória, a forma de conhecimento, norteamento, a falta de equilíbrio emotivo e habilidade se expressar-se (MIRANDA AF e MONTENEGRO FLB, 2009). 
Desta forma, existe a possibilidade de surgir problemas em práticas rotineiras, como banhar-se ou até mesmo ao que se refere ao processo de higienização oral, em que por consequência ocorre o aparecimento da cárie e da doença periodontal, esses fatores são ocasionados devido à falta de capacidade do paciente de possuir como conduta os cuidados essenciais provocando assim na maioria dos casos xerostomia, acarretado pela utilização de fármacos anticolinesterásicos que são substâncias que atuam por meio da inibição da enzima Acetilcolinesterase (SPEZZIA S, 2018).

A Doença de Alzheimer possui sua origem desconhecida, porém sabe-se que ela é induzida por condições sistêmicas e fatores genéticos, tendo como exemplo o sexo, cronologia de ocorrência entre parentes, falta de condições boas no aspecto imunológico do paciente, o avanço da idade, nível escolar, doenças vasculares cerebrais, traumatismo cerebral em que pode ter ocorrido através de acidente e até mesmo os pacientes apresentarem dores de cabeça forte e não ser tratada nem conhecer a causa, neoplasias, preocupações rotineiras no trabalho ou em casa e utilização de drogas ilícitas (SPEZZIA S, 2018).

Essa patologia é uma condição que não apresenta cura, no entanto o engajamento de uma equipe multidisciplinar ajuda de forma significativa o retardo da sua progressão, ajuda no aspecto cognitivo, além de trabalhar nos fatores que representam as mudanças de humor e comportamentais, com o propósito de disponibilizar um melhor bem-estar as peculiaridades de vida do paciente acometido com essa doença (MIRANDA AF e MONTENEGRO FLB, 2009).

\section{Associação entre Doença de Alzheimer e a Doença de Parkinson}

A existência de citocinas existente tanto na Doença de Alzheimer e Doença de Parkinson propõe uma correlação entre essas patologias. Compreende-se que a doença periodontal é capaz de efetivar o avanço da por dois modos: periodontite acarretada por processos inflamatórios sistêmicos ou pela intervenção bacteriana ou viral (GURAV AN, 2014).

Inúmeras pesquisas feitas nos últimos anos demonstraram que indivíduos que apresentam idade elevada com indícios de processos que levam a demência demonstraram estados ruins ao que se refere ao processo de sangramento gengival, a DP, acarreta um maior acréscimo de biofilme e não apresenta colaboração para as atenções orais. Desse modo, foi percebido que a patologia relacionada a problemas Periodontais surgem com bastante continuidade em indivíduos com DA, sobretudo pela carência do conhecimento em preservar uma higiene oral em combinação com a evolução da etiologia (GURAV AN, 2014).

O processo inflamatório é uma característica da neuropatologia que são doenças do tecido do sistema nervoso da Doença de Alzheimer, tendo potencial de serem iniciada por uma discordância localizada no sistema nervoso central (SNC) e/ou por processos infecciosos periféricos. Uma associação eventual entre os fatores patogênicos presente no periodonto e espécimes de bactérias que estão presentes por meio de junções dos $\beta$-amiloides em que são peptídeos com 36-43 aminoácidos e o principal constituinte das placas de amiloide observadas no cérebro de pacientes com DA e os processos inflamatórios. Já a Doença de Parkinson corresponde a uma infecção na cavidade bucal na parte periférica em que pode oportunizar ao cérebro bactérias imaculadas, pontos de virulência e intermédios inflamatórios por causa das bacteremias corriqueiras e transitórias que são acometidas (KAMER AR, et al., 2008).

Estudos feitos por Chen C, et al. (2017) analisou que verificou-se uma evolução do progresso da Doença de Alzheimer depois de 10 anos do laudo de Doença de Parkinson crônica, dos quais foram comprovados uma inter-relação entre essas patologias.

\section{Correlação entre os pacientes, familiares e o CD}

Visto que com o passar do tempo o estado mental do paciente apresenta-se como forma de deterioração e progredindo, o indivíduo portador da DA possui um potencial de incapacidade até no ato de saber administrar as técnicas de higienização bucal corretamente. Diante disso, a disciplina e didática dos familiares ou cuidadores apresentam um papel bastante importante (MONTANDON AFB, et al., 2017). Havendo suma relevância que essas pessoas próximas do portador da DA obtenham uma capacitação apropriada visando a capacidade de assimilar o real problema e encontrarem-se hábeis a aplicar todo o processo de plano de tratamento de forma preventiva sugerido pelo CD (ILHA S, et al., 2010). 
Assim como a capacitação circunda referências sobre a forma certa de se estabelecer uma determinada posição do paciente portador, no momento da efetivação dos procedimentos que foram propostos, estratégias de introdução, removimento e higienizção das próteses devem serem acompanhadas, as técnicas ao que se refere ao ato de escovar os elementos dentais e habilidade para possíveis detecções de lesões predecessora de câncer oral.

Entretanto, as pessoas que cuidam desses pacientes precisam somente verificar e acompanhar o processo de higienização apenas dos pacientes que não são capazes de executar sozinhos, frequentemente, por causa da diminuição das habilidades manuais que eles possuem em retirar as placas bacterianas existentes usando apenas as escovas de dentes e fio dental, tendo que ser mudado as escovas manuais por escovas mecânicas (MIRANDA AF e MONTENEGRO FLB, 2009).

No momento em que o indivíduo portador da DA demonstrar um elevado índice de prevalência de cárie relacionada à xerostomia, é considerável a utilização de flúor pelos CD's. Os produtos encontrados em forma de gel apresentam melhor desempenho quando compara-se a soluções de forma mais liquidas, isso ocorre por exibirem inferior aversão em ocorrer ingestões indesejadas. Pode ser utilizado o fluoreto de sódio (Tratase de um pó cristalino branco em condições ambientes, solúvel em água) a 1\%, sendo empregado com a escova de dente ou até mesmo moldeiras disponibilizadas pelos CD's, ou, pode abrir mão da utilização de vernizes flouretados dos quais possui a finalidade de prolongar o tempo de contato entre o flúor e o esmalte dental (SCANNAPIECO FA e CANTOS A, 2016).

A aplicação de recursos para o paciente executar o bochecho, como é o caso da clorexidina, é benéfico no quesito ao que se refere a diminuição da prevalência de gengivite e doenças periodontais, no entanto, requer uma administração cautelosa por causa dos aspectos neurofisiológicos desses pacientes, visto que a solução não pode ser engolida e sim cuspida. Quando o portador da DA não apresenta nenhuma condição da sua utilização, o responsável pode sobrepor a solução sobre os elementos dentais envolvendo o sulco gengival com a própria escova de dente e bastonetes com gazes (ILHA S, et al., 2010).

\section{A interação entre a Doença de Alzheimer e Doenças Periodontais}

Quando se refere a doença de Alzheimer, diretamente é associado o indivíduo a patologias periodontais pois é uma das mais comuns doenças que acontecem na saúde oral do portador de Alzheimer. Caracterizase contudo por um agente infeccioso que agride toda a cavidade bucal, porém os locais mais específicos dessa agressão estão inseridos especialmente nos tecidos gengivais que envolvem o colo dos dentes e o periodonto de sustentação que são os tecidos que suportam o elemento dentário, dos quais podem possuir seu princípio através de agentes etiológicos ou não, e relevando ocasionalmente infecções das quais apresentam potencial de possuir correlação com o acúmulo de biofilme. Com isso essa circunstância beneficia o processo da reabsorção óssea e por consequência ocasiona perda de alguns ou todos os elementos dentários (GURAV AN, 2014).

A doença periodontal pode esta correlacionada a diversas patologias, como patologias cardíacas que afeta o coração e os vasos sanguíneos, incluindo problemas estruturais e coagulações, a Síndrome de Down, doença de Parkinson e doença de Alzheimer (OLIVEIRA FEC e PAULA TS, 2016). Refere-se em um processo de inflamação, dos quais expõe substâncias endógenas ou exógenas que são libertadas durante a inflamação conhecidas como mediadores de inflamatórios, presentes na corrente sanguínea, cujo avanço pode favorecer na exacerbação de diversas doenças. Posto isto, trabalhos científicos mais vigentes indicam uma junção no processo de inflamações nas partes periféricas e a DA, uma vez que as citocinas que são proteína em que secretada por células e que afeta o desempenho das células vizinhas portadoras de receptores atuam diretamente na periodontite (ROLIM WSF, et al., 2018).

O acréscimo referente aos graus dos processos de mediadores pró-inflamatórias, como o mediador endógeno leucócito, a interleucina-6 (IL-6) e o fator de necrose tumoral alfa (TNF-) em que é um grupo de citocinas capaz de provocar a morte de células (apoptose), recomendam que o processo inflamatório sistêmico crônico seja intensificado prejudicando por sua vez partes do cérebro, dos quais tem potencial para cooperar para o agravamento do avanço da demência do paciente portador da DA (ROLIM WSF, et al., 2018). 
Estudos elaborados por Rangel F, et al. (2012) foram apresentados duas formas de mecanismos em que eles estejam relacionados com o avanço de problemas periodontais e a intervenção na DA, sendo eles: os mediadores inflamatórios e os bacterianos. Levando em consideração o primeiro caso dos quais relaciona os mediadores de inflamações através do mecanismo ocasionado no cérebro, dos quais a sua evolução é acarretada de acordo com a progressão da carga inflamatória da doença periodontal. Enquanto a segunda forma designa que os problemas periodontais podem participar de forma direta no processo de inflamações cerebral, por meio de bactérias.

As espécies que mais provocam problemas relacionados com a periodontia são Actinobacillus actinomycetemcomitans que é uma bactéria Gram-negativa, anaeróbica facultativa, imóvel, geralmente encontrada em associação com periodontite agressiva localizada, em infecções graves do periodonto, as Porphyromonas gingivalis das quais são bactérias Gram-negativas, possui forma de bacilo, é anaeróbico e patogênico, geradora de colônias escuras em ágar sangue, as Treponema denticola que são bactérias onde apresentam espiroqueta Gram-negativa, anaeróbica, móvel e altamente proteolítica obrigatória e Fusobacterium nucleatum que faz comensal à cavidade oral humana, que desempenha um papel na doença periodontal, esses quatro tipos são aptos de se proliferarem até o cérebro e incentivar as citocinas próinflamatórias e, com isso, cooperar para os processos de mediação patogênica da (SENSEVER F, et al., 2018).

\section{Desempenho do Cirurgião Dentista em pacientes com DA, de acordo com o seu nível de progressão}

Geralmente, o CD depara-se com duas situações, inicialmente é na ocasião em que o portador da doença de Alzheimer dispunha antecedentemente à essa patologia de um quadro satisfatório de saúde oral e encontrava-se acostumado a ir a clínica odontológica rotineiramente. À vista disso, é de suma importância que esse costume seja continuado por eles e estimulado pelos responsáveis, para que possua a preservação a condição de saúde oral. E a segunda, porém não menos importante é quando o paciente já possui uma predisposição ou possui a doença da cavidade bucal. Desta maneira, a hipótese do prognóstico baseado necessariamente no diagnóstico do $C D$ e nas possibilidades terapêuticas não será tão boa, isso ocorre porque além da superior problema em ajudar no estado do paciente, não possui relação do paciente com o profissional e o processo terapêutico, e em conformidade com o nível da DA, só é viável a execução de procedimentos em momentos críticos (BLENNOW K, et al., 2006).

Desta forma é de suma importância que o Cirurgião dentista saiba o estado e fase em que o paciente se encontre, para só assim distinguir sobre as inevitabilidade de cada paciente de forma particularizada, buscando sempre obter um melhor tratamento, buscando considerar determinados aspectos de ponderação que conseguirão sugestionar nas condutas preventivas e/ou no tratamento de melhora apresentados (CERAJEWSKA TL, et al., 2015).

\section{Fase inicial}

Nessa respectiva fase da patologia da qual pode ter sua durabilidade de até quatro anos é ocasionado a perda progressiva das memórias mais atuais. Mesmo ocorrendo o envolvimento do comprometimento inicial, 0 indivíduo nesse momento pode submeter-se aos procedimentos odontológicos. Na primeira consulta o profissional deve estar ciente da fase em que o paciente se encontra, buscar conversar com ele e com os familiares ou cuidadores para só assim dá início depois da anamnese a primeira sessão, sendo levado em consideração que a parte preventiva deve ser feita nessa respectiva fase, devido a melhor inter-relação, colaboração com o paciente, sobretudo os pacientes que já possuem uma vivencia na clínica odontológica, conseguindo em muitos casos executar até mesmo atividades lúdicas para uma melhor interação e aproximação entre o Cirurgião dentista e o paciente (MIRANDA AF, et al., 2010).

Recomenda-se fazer o preparo e nortear o paciente portador da Doença de Alzheimer de todas as maneiras viáveis objetivando um possível avançamento da patologia futuramente, tendo como exemplo, nortear sobre a instrução e motivação da higiene oral, falar a respeito dos danos que o biofilme pode ocasionar, ter cuidado sobre a redução do biofilme, executar restaurações defeituosas ou que estejam velhas, fazer o diagnóstico e elaborar um planejamento de tratamento periodontal, se existir determinadas patologias é importante serem tratadas e analisar a funcionalidade das próteses (CERAJEWSKA TL, et al., 2015). 


\section{Fase intermediária}

Nesta etapa, o indivíduo portador da Doença de Alzheimer não contribui com o recurso terapêutico estabelecido tornando-se supostamente imprescindível a utilização de processos de sedações em determinadas condutas feita pelos Cirurgiões Dentistas. À vista disso, a forma de se executar as condutas de planejamentos dessas condições estabelecidas devido o quadro exibido pelos pacientes devem serem pensavas, tendo uma equipe multiprofissional envolvida.

Tendo como o foco principal o bem-estar do paciente recomenda-se a utilização de sedação com óxido nitroso, podendo optar-se por utilização de fármacos como os benzodiazepínicos e ansiolíticos, evitando assim um possível estresse do paciente portador da DA e favorecendo de forma bastante significativa os provimentos na clínica odontológica (FRENKEL H, 2004).

Nessa etapa é importante que o CD possua uma conduta clínica bastante focada, tendo como principal idealização a retirada de possíveis focos de doença periodontal, por meio de raspagens supragengivais em que se realiza para retirada do tártaro da parte mais visível do elemento dental, sendo prescrita para quando o paciente não apresenta bolsa periodontal, ou seja, quando os ossos que estão em volta dos dentes ainda não começaram a serem prejudicados, sendo conhecida nessa fase como gengivite e subgengivais em que é feito a retirada dos tártaros que estão localizados abaixo da linha da gengiva em que já ocorre a reabsorção óssea de suporte dos dentes, essa fase já encontra-se a periodontite e nessa fase intermediária também é feita a supressão, seja qual fator for que consiga constituir qualquer probabilidade de sofrimento ao paciente portador da DA (ROLIM WSF, et al., 2018).

\section{Fase final}

O último estágio da doença determina-se por desnorteamento excessivo do paciente, apresentando falta de emoção, motivação ou entusiasmo, expondo total dependência de familiares ou cuidadores, utilização de fraldas ocasionada pela perda do controle fecal e urinário e esquecimento por completo de episódios ocorridos recentemente, na maioria das ocasiões ocorre o desmemoriam seus próprios familiares. O portador da DA habitualmente é violento e apresenta um quadro de ansiedade muito elevado, podendo acontecer processos de desnutrição (CESTARI JA, et al., 2016).

A ação do CD neste momento é fundamental a respeito de sua verdadeira essencialidade e possui como caráter crucial no desenvolvimento de medidas paliativas em pacientes com essa doença. As pequenas condutas referentes a saúde oral necessitam serem preservadas, uma vez que os pontos de infecção dos elementos dentários possuem elevado impacto na saúde de forma geral.

Tal como, ocorrências de mortalidades relacionados a quadros de pneumonia aspirativa devido à quebra da defesa pulmonar em pessoas com maior idade e inexistência de uma boa situação de saúde bucal desses indivíduos (NUNES LM e PORTELLA MR, 2003).

Nessa fase procedimentos que requerem um maior prolongamento de tempo devem serem rejeitados, havendo a interceptação do CD exclusivamente para a retirada de possíveis focos infecciosos e sintomas etiológicos que prejudica ainda mais a situação de saúde geral do indivíduo portador de DA (SCANNAPIECO FA e CANTOS A, 2016).

\section{CONSIDERAÇÕES FINAIS}

Por causa das perdas referentes aos processos mentais que não permitem o paciente desenvolver qualquer atividade e observando a grande dificuldade presente ao que se refere a higienização da cavidade bucal, os pacientes que apresentam Doença de Alzheimer são mais vulneráveis a possuírem problemas relacionados com cárie e doenças periodontais. Assim sendo, no sentindo de se estabelecer um seguimento favorável para a saúde desses indivíduos o CD precisa entender o dinamismo da DA, sendo levado em consideração a forma particularizada que ocorre de um paciente para outro, o estágio e gravidade que 0 mesmo encontra-se, para analisar esses fatores, esses profissionais precisam estar devidamente capacitados e qualificados, buscando atender de forma mais humanizada possível. 


\section{REFERÊNCIAS}

1. BLENNOW K, et al. Alzheimer's disease. The Lancet, 2006; v. 368, n. 9533: 387-403.

2. CERAJEWSKA TL, et al. Periodontitis: potential risk factor of Alzheimer's disease. British Dental Journal, v. $2018 ; n$. 1: 29-34.

3. CESTARI JÁ, et al. Oral Infections and Cytokine Levels in Patients with Alzheimer's Diseaseand Mild Cognitive Impairment Compared with Controls. J Alzheimer Dis, 2016; v. 52, n 4: 1479-1485.

4. CHEN C, et al. Association between chronic periodontitis and the risk of Alzheimer's disease: a retrospective, population-based, matched-cohort study. Alzheimer's Research \& Therapy, 2017; v. 56: 1-7.

5. DIAS MHMS, FONSECA SC. Atendimento de pacientes com doença de Alzheimer na clínica odontológica: desafios e diretrizes. Geriatria \& gerontologia, 2011; v. 5: 34-39.

6. FEART C, et al. Associations of lower vitamin D concentrations with cognitive decline and long-term risk of dementia and Alzheimer's disease in older adults. Alzheimer's \& Dementia.2017;129(1): 46-50.

7. FRENKEL H. Alzheimer's disease and oral care. Dent Update. 2004; 31(5):273-278.

8. GURAV AN. Alzheimer's disease and periodontitis - an elusive link. Rev. Assoc. Med. Bras., São Paulo, 2014; v. 60, n. 2: 173-180.

9. ILHA S, et al. Percepções de acadêmicos das atividades interdisciplinares realizadas no grupo de cuidadores de idosos com Alzheimer. Disciplinarum Scientia. Série: Ciências da Saúde, Santa Maria, 2010; v.11, n.1: 25- 36.

10. KAMER AR, et al. Alzheimer's Disease and peripheral inections: the possible contribution from periodontal infections, model and hypothesis. Journal of Alzheimer's Disease, 2008; v. 13, n. 4: 437-449.

11. MIRANDA AF, et al. Doença de Alzheimer: características e orientações em odontologia. Revista Gaúcha de Odontologia, Porto Alegre, 2010; v. 58, n.1.

12. MIRANDA AF, MONTENEGRO FLB. Atuação odontológica na doença de Alzheimer: relato de caso clínico multidisciplinar. Int J dent, Recife, 2009; 8(4): 220-224.

13. MONTANDON AFB, et al. Abordagem odontológica do idoso com demência: elementos de rotina preventiva para redução de comorbidades. In: V Congresso Internacional de Envelhecimento, 2017, Maceió- Alagoas. Anais V CIEH, 2017; v. 1: 1-12.

14. NUNES LM, PORTELLA MR. O idoso fragilizado no domicílio: a problemática encontrada na atenção básica em saúde. Bol Saúde. 2003; 17(2): 109-121.

15. OLIVEIRA FEC, PAULA TS. Periodontite agressiva relacionada a outras doenças: uma revisão de literatura. Revista Diálogos Acadêmicos, Fortaleza, 2016; v.5, n.2.

16. RANGEL F, et al. Inflamação e Mal de Alzheimer: possível papel da doença periodontal. Brazilian Journal Periodontology, 2012; v. 22, n. 2: 41-46.

17. ROLIM WSF, et al. A relação entre a doença de Alzheimer e a Periodontite - Revisão de Literatura. Anais da Jornada Odontológica dos Acadêmicos da Católica, Quixadá, 2018; V.4, N.1.

18. SCANNAPIECO FA, CANTOS A. Oral inflammation and infection, and chronic medical diseases: implications for the elderly. Periodontology 2000, 2016; v. 72, n. 1; 153-75.

19. SENSEVER F, et al. Associação da doença periodontal e doença de Alzheimer. Disciplinarum Scientia. Série: Ciências da Saúde, Santa Maria, 2018; v. 19, n. 1:113-124.

20. SILVA RAC, et al. Aspectos odontológicos a serem considerados para o tratamento de portadores da doença de Alzheimer. Full Dent. Sci, 2015; 6(24): 550-555.

21. SPEZZIA S. Saúde bucal e doença de Alzheimer. Rev Fac Ciênc MédSorocaba. 2018; 20(4): 191-194.

22. TURNER LN, et al. Drug therapy in Alzheimer disease: an update for the oral health care provider. Oral Surg Oral Med Oral Pathol Oral Radiol Endod; 2008; 106(4): 467-76. 